\title{
A DIMENSÃO TEÓRICA DA FORMAÇÃO DOS FORMADORES EM DIDÁTICA E PRÁTICAS DE ENSINO: INFLUÊNCIAS NO PENSAMENTO CONTEMPORÂNEO E REPERCUSSÕES NAS PRÁTICAS DE FORMAÇÃO ${ }^{1}$
}

\author{
TÂNIA Maria BaIBICh-FARIA* \\ Recebido em: 03 de julho de 2009 \\ Aprovado em: 05 de outubro de 2009 \\ * Dra. em Psicologia Social pela Universidade de São Paulo (2001). Pós-doutora em Preconceito na Escola, \\ na Universidade de Michigan (2003) e em Pedagogia do Ensino Superior na Universidade do Rio dos Sinos \\ (2008). Prof ${ }^{a}$ Associada II da Universidade Federal do Paraná. E-mail: tbaibich@terra.com.br.
}

Resumo: Identifica e analisa os referentes teóricos que os autores nacionais, professores simposistas do XV Encontro Nacional de Didática e Práticas de Ensino 2008, utilizam para qualificar práticas de formação, em especial da educação superior. Analisa como esses referentes influenciam a produção brasileira contemporânea e são reconhecidos no pensamento e produção de 46 simposistas que responderam aos questionários, via correio eletrônico. Levando em conta os resultados das informações obtidas no campo empírico, é possível indicar pelo menos quatro grupos de análise que podem ajudar na sistematização das respostas: os livros mais importantes na formação; os brasileiros mais citados na área; os estrangeiros preferenciais nas atividades como docente/ pesquisador e os brasileiros preferenciais nas atividades como docente/pesquisador. Guardadas as distintas especificidades, a preocupação com as relações entre saber e poder bem como com a historicidade da formação do professor dá-se de maneira contundente. Há, de parte dos sujeitos dessa pesquisa, o que se pode denominar de "sujeitos endereço" na área da Didática e das Práticas de Ensino no país, que defendem uma explícita opção epistemológica voltada às teorias críticas e/ou pós-críticas e pós-colonialistas que permitem ver a educação de uma nova perspectiva ao retirarem o foco de conceitos simplesmente pedagógicos de ensino e aprendizagem e colocaremno na análise dos conceitos de ideologia e poder. Observa não haver na comunidade epistêmica analisada endogenia ou colonização e que autores brasileiros são reconhecidos como referência para todas as áreas do ENDIPE.

Palavras-chave: Referentes teóricos. "Sujeitos Endereço" em didática e práticas de ensino. Comunidade epistêmica.

THE THEORETICAL DIMENSION OF THE TEACHER'S EDUCATION IN DIDACTIS AND TEACHING PRACTICES: INFLUENCES ON CONTEMPORARY THINKING AND IMPACT ON TEACHING PRACTICES

\begin{abstract}
This article identifies and analyzes the theoretical referents that national authors, more specifically the professors who spoke at the XV National Encounter of Didactics and Teaching Practices (ENDIPE), 2008, use in order to qualify educational practices, especially in higher education. It analyzes how these referents influence contemporary Brazilian production and how they are recognized in the thoughts and production of the 46 symposiasts who answered the questionnaires, by means of electronic mail. Considering the results from the data obtained in the empirical field, it is possible to point out at least four analytical groups that could help in the systematization of

1 Trabalho resultante de estágio de Pós-Doutorado no PPGE da UNISINOS, de agosto a novembro de 2008, sob orientação da Professora Dra. Maria Isabel da Cunha, apresentado no Encontro da RIES em Mesa Redonda intitulada: "Qualidade da docência e qualidade do ensino", na UNISINOS, em maio de 2009. Agradeço à muito querida e admirada Professora Maria Isabel da Cunha pelas críticas e sugestões fundamentais e me responsabilizo por todas as afirmações e análises aqui apresentadas para o debate.
\end{abstract}




\begin{abstract}
the answers: the most important books used in undergraduate studies; the most cited Brazilian authors in this field; the preferred foreign authors in the activities as teacher/researcher; and the preferred Brazilian authors in the activities as teacher/researcher. Specificities aside, the concern with the relation between knowledge and power, as well as with the history of teacher education occur in an impressive manner. There are, according to the subjects of this research, what could be named as "address-subjects" in the fields of Didactics and Teaching Practices in the country, who defend an explicit epistemic choice of critic and/or post-critic and post-colonialist theories that allow us to see education in a new perspective, as they remove the focus from merely pedagogical concepts of teaching and learning and turn it to the analysis of the concepts of ideology and power. It is observed that there is no endogeny or colonization in the epistemic community analyzed and that Brazilian authors are recognized as references in all the fields comprehended in the ENDIPE.
\end{abstract}

Key words: Theoretical Referents. "Address-Subjects” in didactics and teaching practice. Epistemic community.

\title{
1 Introdução
}

Ao participar de um Simpósio do último ENDIPE ${ }^{2}$ tomamos conhecimento de um estudo (ANDRÉ, 2008) com dados sobre a circulação da produção científica da área da educação através, entre outros indicadores, das citações em teses e dissertações, dos autores nacionais e estrangeiros.

Esses dados provocaram uma curiosidade inicial sobre os referentes teóricos que os autores nacionais, que vêm influenciando a produção contemporânea, reconhecem em seu pensamento e produção. Dessa "aproximação precária" (FARIA, 2009) ${ }^{3}$, amadureceu a idéia de identificar as representações e referências que estão presentes nos autores que qualificam as práticas de formação, em especial da educação superior, buscando identificar as bases teóricas que sustentam os indicadores de qualidade do ensino e da pesquisa e as ações de desenvolvimento dos mesmos.

Tomando em conta que o ENDIPE constitui-se em um encontro eclético, sem fronteiras rígidas entre disciplinas, elegeu-se como público alvo os Simposistas do XIV ENDIPE (PUC-RS, 2008), por considerá-los uma população representativa desse universo orientador de um campo de conhecimento que se refere à Didática, às Práticas de Ensino e à Formação de Professores. Foram enviados 204 questionários, via correio eletrônico, para os simposistas brasileiros. Do total enviado, 46 (22,5\%) foram respondidos e analisados ${ }^{4}$.

2 Encontro Nacional de Didática e Práticas de Ensino.

3 Agradeço ao Professor Dr. José Henrique pelas críticas e sugestões às análises aqui empreendidas, sempre extremamente valiosas e bem-vindas, e me responsabilizo por todas as afirmações aqui apresentadas. 4 Agradeço enfaticamente a participação de todos os professores que participaram da presente pesquisa na qualidade de sujeitos e menciono os que autorizaram a menção de seus nomes e o uso explicitado de suas 
O XIV ENDIPE foi dividido em sete áreas, a saber: Pesquisa e Construção do Conhecimento em Didática; Práticas de Ensino e Didáticas Específicas; Formação de Professores e Saberes Docentes; Sujeitos do Processo de Ensinar e Aprender; Políticas Públicas e Institucionais e os Processos Educativos; Currículo Cultura e Diferença nos Lugares e Espaços Educativos; Ensinar e Aprender no Meio Virtual e Outras Linguagens. ${ }^{5}$

Procuramos, inicialmente, conhecer a trajetória de formação dos professores simposistas, com o intuito de localizar a matriz de seus possíveis referentes, numa perspectiva histórica e geográfica. Alguns dos dados são explicitados nos quadros a seguir:

\section{Instituição de Doutoramento}

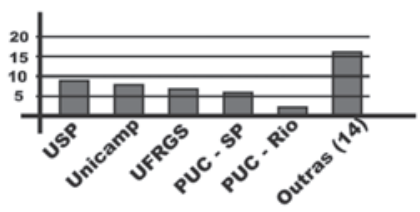

Tempo de Doutoramento

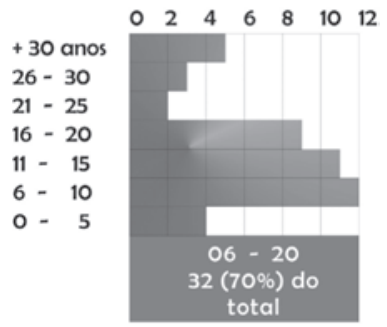

\section{País de Doutoramento}

39

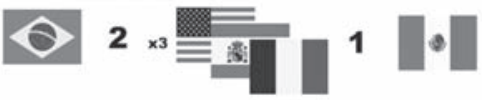

\section{Pós Doutoramento}

País de Pós-Doutoramento
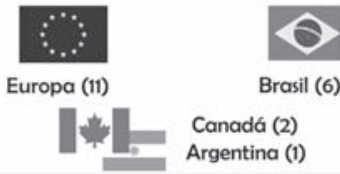

Brasil (6)

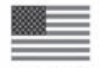

EUA (4)

Canadá (2)

Argentina (1)

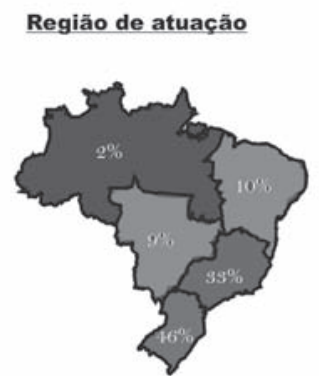

Fonte: A autora (2009)

manifestações, abaixo, em ordem alfabética: Alda Marin; Alice Casimiro Lopes; Antonio Vicente Marafioti Garnica; Beatriz Daudt Fischer; Bernardete Angelina Gatti; Celi Nelza Zulke Taffarel; Cleoni Maria Barbosa Fernandes; Corinta Maria Grisolia Geraldi; Emilia Maria de Trindade Prestes; Eurize Caldas Peçanha; Gabriel de Andrade Junqueira Filho; Ilma Passos Alencastro Veiga; José Carlos Libâneo; Leda Scheibe Lílian Anna Wachowicz; Lucia Maria Vaz Peres; Maria de Fátima Barbosa Abdalla; Maria Isabel da Cunha; Maria Helena Câmara Bastos; Maria Helena Wagner Rossi; Maria Leila Alves; Márcia Ondina Vieira Ferreira; Mari Forster; Maria da Conceição Ferreira Fonseca; Marisa Vorraber Costa Marília Claret Geraes Duran; Marilda Oliveira de Oliveira; Marli Eliza Dalmazzo Afonso de André; Nestor André Kaercher; Newton César Balzan; Nidia Nacib Pontuschka; Nágila Caporlíngua Giesta Rosalba Maria Cardoso Garcia; Rosália Duarte; Rosangela Tenório de Carvalho; Selva Guimarães Fonseca; Sonia Meiri Santos Azevedo de Jesus; Tânia Maria Esperon Porto e Vânia Alves Martins Chaigar.

5 Para fins de análise dos dados, em alguns momentos trabalhou-se com a população total de sujeitos e em outros os dividindo pelas diferentes áreas na intenção de observar possíveis diferenças e semelhanças. 
Conforme se observa, os respondentes na sua maioria, afirmaram terem se doutorado no Brasil (39 casos), especialmente mencionando a USP, UNICAMP, PUC-SP, UFRGS e UFRJ como sendo as Instituições que os recebeu. A formação de doutorado parece ser de muita importância na carreira do pesquisador, pois essa fase marca a maturidade intelectual do sujeito, revelada nas suas escolhas temáticas e conceituais. Já os programas de pós-doutorado, realizados pela metade dos professores entrevistados (23 casos) têm seu peso na Europa (11 casos). É importante observar, nesse sentido, que seis dos sujeitos pesquisados tenham realizado o pós-doutoramento no Brasil, o que pode indicar tanto uma tendência de restrições orçamentárias por parte das agências financiadoras, quanto uma tendência de valorização dos Programas brasileiros ${ }^{6}$.

Os simposistas, professores sujeitos da pesquisa, aqui considerados como representantes da comunidade epistêmica (ANTONIADES, 2003; DIAS, 2008; LOPES, 2006) são em sua maciça maioria doutores seniores, com reconhecida experiência acadêmica, pois $72 \%$ possuem entre seis a vinte anos de formação e $21,7 \%$ têm entre vinte e um e trinta anos de doutoramento.

Do total de respondentes, $79 \%$ dos professores atuam em instituições localizadas nas regiões Sul e Sudeste, seguidas por Nordeste, Centro-Oeste e Norte. O fato de o XIV ENDIPE ter ocorrido na região Sul pode explicar, em parte, a forte presença dessas regiões, facilitando o deslocamento dos participantes. Contudo, convém registrar a influência do Sudeste e do Sul que vem sendo contabilizada em outros estudos e nas próprias estatísticas oficiais.

Levando em conta os objetivos que motivaram o estudo, pareceu importante conhecer os referenciais teóricos que mais influenciaram aqueles que, por sua vez, também vêm influenciando a formação de novos pesquisadores no Brasil. Por essa razão, solicitamos que indicassem os cinco livros/autores considerados os mais importantes em sua formação, explicando as razões dessa escolha. Para facilitar a compreensão dos dados, elaboramos o Quadro "Livros/autores mais indicados na formação", que explicita as escolhas, em ordem decrescente, considerando a soma de indicações: ${ }^{7}$

6 Certamente, essa é uma questão que merece ser melhor investigada, pois pode contribuir para o estabelecimeto de políticas públicas de financiamento de programas de pós-doutoramento.

7 Houve professores que indicaram mais ou menos do que cinco autores, houve quem indicasse o autor e alguma/s obra/s. Houve várias indicações que apareceram apenas uma vez e que não serão analisadas neste trabalho por problemas de espaço. 


\begin{tabular}{|lc|}
\hline Autores & Indicações \\
\hline Paulo Freire & $21^{*}$ \\
\hline Karl Marx & 13 \\
\hline Pierre Bourdieu & 12 \\
\hline Dermeval Saviani & 09 \\
\hline Antonio Gramsci & 08 \\
\hline Michael Foucault & 07 \\
\hline Boaventura de Souza Santos & 06 \\
\hline Karel Kosik & 05 \\
\hline Antonio Nóvoa; Gaston Bachelard; George Snyders & 04 \\
\hline $\begin{array}{l}\text { Carl Rogers; H. Lefébvre; Jean Piaget; Lev Vygotsky; } \\
\text { Louis Althusser; Max Weber; Tomás Tadeu da Silva }\end{array}$ & 03 \\
\hline $\begin{array}{l}\text { Agnes Heller; Ana Mae Barbosa; Carlo Guinzburg; Edgar Morin; } \\
\text { Fernando Henrique Cardoso; Hanna Arendt; Humberto Maturana; } \\
\text { José Dias Sobrinho; J. Gimeno Sacristán e A. I. Pérez; } \\
\text { Jacques Le Goff; Jorge Larrossa; José Carlos Libâneo; } \\
\text { Marilena Chauí; Michael Apple; Michael Certeau; Miriam Limoeiro; } \\
\text { Otavio lanni; Stuart Hall }\end{array}$ & 02 \\
\hline
\end{tabular}

Quadro 1: Livros/autores mais indicados na formação

Fonte: A autora (2009).

Nota: Somente o livro "Pedagogia do Oprimido" teve nove indicações.

Essa primeira indicação revela uma interessante tendência geracional e pode servir para cotejamento de outros estudos, ou de ampliação da amostra. O destaque a Paulo Freire é relevante e reafirma a importância do pensador brasileiro como fonte principal de compreensão do fenômeno educativo. Também ficam evidentes as implicações da teoria crítica nas indicações dos respondentes e demonstra uma certa amplitude de teóricos que povoam, ainda no momento atual, estudos e pesquisas educacionais.

Como o ENDIPE se organizou explicitando sete estruturantes temáticos que, por sua vez, reúnem comunidades específicas de pensadores, pareceu interessante indagar sobre os teóricos influenciadores mais recorrentes, por cada um desses estruturantes. Procurávamos identificar aproximações ou especificidades reconhecidas pelos sujeitos.

Percebemos, então, que Paulo Freire recebeu citações nas sete áreas, seguido por Demerval Saviani, presente em cinco áreas. Em duas áreas foram citados

8 Citados conjuntamente como uma dupla.

9 Também sujeito da presente pesquisa. 
autores brasileiros como Ana Mae Barbosa; Ana Maria Carvalho; Antonio Candido; Antonio Flávio Moreira; Bárbara Freitag; Eni Orlandi; Florestan Fernandes; Gelsa Knijnik; Heloísa Penteado; José Carlos Libâneo ${ }^{10}$; José Dias Sobrinho; José Mario P. Azanha; Josué de Castro; Lauro de Oliveira Lima; Luiz Antonio Cunha; Luiz Carlos de Freitas; Madalena Freire; Magda Soares; Maria Alice Foracchi; Maria Célia Marcondes de Moraes; Maria Lúcia Santaella Braga; Marilena Chauí; Marli André ${ }^{11}$, Menga Lüdke ${ }^{12}$; Martha Pessanha; Maurício Tragtenberg; Miriam Limoeiro; Moacyr Gadotti; Newton Balzan ${ }^{13}$; Otávio Ianni; Sonia Kraemer e Tomás Tadeu da Silva.

Entre os citados em uma área estão Álvaro Vieira Pinto (Sete lições de Educação para Adultos); Ana Maria P. Carvalho; Antonio Candido; Antonio Flávio B. Moreira; Bárbara Freitag; Caio Prado; Carlos Vesentini; Celso Furtado; Eni Orlandi; Fernando Henrique Cardoso; Florestan Fernandes e Ernani Fiori ${ }^{14}$; Gelsa Knijnik; Gilberto Freire (Casa Grande e Senzala); Guiomar N. Mello; Ira Schor ${ }^{15}$ (Medo e Ousadia); José Mário P. Azanha; Josué de Castro; Lúcia Santaella (O que é Semiótica); Lilian do Vale; Luiz Carlos de Freitas; Madalena Freire (A Paixão de Conhecer o Mundo); Machado de Assis (Contos); Magda Soares; Marcos Silva; Maria Célia Marcondes Moraes; Maria Isabel da Cunha ${ }^{16}$; Mauricio Tragtenberg; Miguel Arroyo; Milton Santos; Moacyr Gadotti; Newton Balzan ${ }^{17}$; Roseli Pacheco Schnetzler; Rui Mauro Marin; Rui Moreira (O discurso do avesso); Sandra Corazza; Sérgio Buarque de Hollanda (Raízes do Brasil); Sonia Kraemer (Com a Pré-Escola nas Mãos); Sonia Penin; Vera Candau ${ }^{18}$.

Dentre os autores estrangeiros mais citados como referência para a docência e para a pesquisa (até um total de três citações) encontram-se Boaventura de Souza Santos e Michel Foucault com 10 indicações; Pierre Bourdieu com 6 indicações; Antonio Nóvoa com 5 indicações; Kenneth Zeichner; Lev Vygotsky com 4 indicações; Carlos Marcelo Garcia; Karl Marx; Michael Apple; Michel de Certeau com três.

Importante ressaltar aqui que Boaventura de Souza Santos, Foucault, Bour-

\footnotetext{
10 Sujeito da presente pesquisa.

11 Sujeito da presente pesquisa.

12 Autoras citadas conjuntamente como constituindo um par.

13 Sujeito da presente pesquisa.

14 Autores citadas conjuntamente como constituindo um par

15 Co-autoria com Paulo Freire.

16 Sujeito da presente pesquisa

17 Sujeito da presente pesquisa

18 Importante ressaltar que cinco sujeitos da presente pesquisa foram apontados como "formadores dos formadores" em pelo menos uma das áreas do ENDIPE, o que indica que o Bom Professor efetivamente continua sempre na postura de quem "de repente aprende".
} 
dieu, Nóvoa, Vygostsky, Marcelo Garcia e Marx foram também citados como importantes na formação dos professores, o que pode ser constatado na Quadro 2 abaixo, que apresenta uma visão comparativa dos dados:

\begin{tabular}{|l|r|r|}
\hline Autores & D/P & F \\
\hline Boaventura de Souza Santos & 10 & 6 \\
\hline Michel Foucault & 10 & 7 \\
\hline Pierre Bourdieu & 6 & 12 \\
\hline Antonio Nóvoa & 5 & 4 \\
\hline Kenneth Zeichner & 4 & - \\
\hline Lev Vygotsky & 4 & 3 \\
\hline Carlos Marcelo Garcia & 3 & 1 \\
\hline Karl Marx & 3 & 13 \\
\hline Michael Apple & 3 & 2 \\
\hline Michel de Certeau & 3 & - \\
\hline
\end{tabular}

Quadro 2: Visão comparativa dos dados

Fonte: A autora (2009).

Considerando as sete áreas do ENDIPE, os autores brasileiros considerados como sendo os mais citados nas respectivas áreas de atuação dos sujeitos da pesquisa são os seguintes: Paulo Freire, Gaudêncio Frigotto; Marli André; Maria Isabel da Cunha em seis (6) das sete áreas. Vale lembrar que Marli André, Maria Isabel da Cunha e Paulo Freire foram também citados como importantes na qualidade de autores/professores formadores dos sujeitos pesquisados.

Dermeval Saviani e Menga Lüdke foram citados em cinco (5) das sete áreas. Ambos também citados como mais importantes na formação. Acácia Kuenzer; Antônio Flávio Moreira; Tomás Tadeu da Silva, foram citados em quatro (4) áreas, sendo que Moreira e Tadeu da Silva também foram indicados como mais importantes na formação. Bernadete Gatti ${ }^{19}$; Guacira Louro; Ilma Veiga ${ }^{20}$; José Carlos Libâneo; Maria Helena de Souza Patto; Marisa Vorraber da Costa ${ }^{21}$; Selma Garrido Pimenta; Terezinha Rios e Vera Candau foram citados em três (3) das sete áreas, sendo que tanto Libâneo quanto Candau foram citados como mais importantes na formação. Alfredo Veiga Netto; Ana Mae Barbosa; Denise Cattani; Miguel Arroyo; Nilda Alves e Vítor Paro foram mencionados em duas (2) das sete áreas, sendo que Miriam Limoeiro e Ana Mae Barbosa também foram citadas como mais importantes na formação e em uma área de atuação foi mencionada a professora Maria Rita de Oliveira. ${ }^{22}$

19 Sujeito da presente pesquisa.

20 Sujeito da presente pesquisa.

21 Sujeito da presente pesquisa.

22 Oito dos mais citados foram sujeitos da presente pesquisa. 
Pareceu ser um dado relevante saber dos interlocutores, que autores ou obras eles não mais recorrem para indicação aos seus alunos ou para uso nas suas pesquisas. Ao responderem eles trouxeram algumas especificidades que merecem ser explicitadas:

a) chamaram a atenção que alguns dos livros mencionados se caracterizam por serem "datados", isto é, reconhecidos como muito importantes outrora, mas que, entretanto, "hoje explicam pouco", "são defasados", "anacrônicos", "pobres";

b) outros, dado sua natureza "tecnicista", não respondem mais à perspectiva contemporânea de prática pedagógica. Correspondem a "época da engenharia da educação, [do qual] não faço mais uso porque tenho uma compreensão didática diferente do lugar que representa a técnica hoje na prática pedagógica, como algo que não é neutro e desinteressado e que também tem seu valor relativo na prática diante do quê, do porquê, do para quê.";

c) há ainda os que foram abandonados devido ao amadurecimento pessoal e/ou mudança de referencial teórico-metodológico ou de foco de pesquisa dos nossos interlocutores. Um deles afirmou: "hoje penso na educação para além do foco ensino-aprendizagem e das abordagens críticas" Enquanto para outro a justificativa se dá porque esses livros "não correspondem mais aos princípios teóricos que sustentam meus estudos" e/ou "no momento lido com outras questões";

d) também questões de caráter de coerência entre produção teórica e ação política dos autores foram apontadas como motivadoras de inadequação. Como afirmou um dos sujeitos da pesquisa: "Tenho o hábito invencível de conferir a coerência entre o que escrevem e o que vivem os autores, quando isso é possível, e [no caso] o foi”.

Especificamente com relação aos autores outrora importantes, mas não mais utilizados, os motivos para justificar a não adequação foram basicamente a "limitação de abordagem" e/ou o fato do autor mesmo ter se "revisitado". As afirmativas de nossos parceiros da pesquisa demonstram que os professores/pesquisadores vivem processos reflexivos que impactam as suas escolhas teóricas e essa condição tem repercussão nas suas produções e na formação de seus alunos. 


\section{Arriscando algumas categorias de análise}

Levando em conta os resultados das informações obtidas no campo empírico, é possível indicar pelo menos quatro grupos de análise que podem ajudar na sistematização das respostas: (a) os livros mais importantes na formação; (b) os brasileiros mais citados na área; (c) os estrangeiros preferenciais nas atividades como docente/pesquisador e (d) os brasileiros preferenciais nas atividades como docente/pesquisador.

Tendo em vista esses quatro agrupamentos, parodiando Freud (1976, p. 253), no desejo de "entender a obra à minha própria maneira", busco categorizar os argumentos utilizados pelos simposistas do ENDIPE no intuito de justificar suas escolhas. As respostas permitiram definir nove categorias, que serão a seguir analisadas. Ilustro cada categoria com algumas falas dos professores respondentes, as quais reputo como verdadeiras aulas de leitura para nós professores/ pesquisadores e para nossos estudantes.

CATEGORIA I: Estruturação do Conhecimento e Compreensão da Realidade e da Significação do Agir e do Saber:

Foram 177 respostas classificadas nessa categoria que é aqui definida como "a condição de organização, reorganização, alargamento, aprofundamento e revisão do conhecimento”. Essa condição resulta na capacidade de análise da realidade, de síntese consistente da complexidade do real e, ao mesmo tempo, de apresentação de discussão sobre o significado da existência da ação humana e do próprio conhecimento. Disseram os respondentes:

Humberto Maturana e seus textos mostraram novas perspectivas sobre a construção do conhecimento humano. Hanna Arendt, especialmente os volumes de A Vida do Espírito. Compreensão sobre os condicionantes históricos, políticos e sócio-culturais sobre as formas do pensar e agir humanos. Compreensão sobre o papel da educação e o sentido de 'liberdade'. (GATTI, B., 2009, pesquisa de campo)

Pedagogia do Oprimido; Medo e Ousadia; O cotidiano do professor; Ciência e existência; Natureza do espaço: tempo, razão, técnica e emoção (acho que é isso); Interpretação das Culturas, Intelectuais e a Organização da Cultura. Antonio Gramsci, Álvaro Vieira Pinto, Paulo Freire, Milton Santos e Clifford Geertz, também Walter Benjamin. Considero que com estes autores tenho condições de uma discussão ontológica que favorece sínteses entre ciência, filosofia e educação com uma lente antropológica social. (FERNANDES, C.M.B., 2009, pesquisa de campo) 
O(s) livro(s) de Caio Prado me fizeram descobrir O QUE DE FATO É História, isto é, uma Ciência, que nada, absolutamente nada tinha a ver com as disciplinas de História que eu estudava na [universidade]. (BALZAN, N.C., 2009, pesquisa de campo)

Paulo Freire: pela coerência entre comprometimento sócio-político e fundamentação epistemológica. [...] Antônio Nóvoa, por ter sido o primeiro autor que referiu com competência (teórica e também metodológica) a questão da dimensão histórica da formação de professores. Piaget (na década de 80), por ter me aproximado de questões epistemológicas consistentes e inovadoras. Lauro de Oliveira Lima (na década de 70), por ter trazido provocações altamente significativas, fazendo-me repensar sobre a) questões do ensinaraprender; b) questões acerca da dinâmica dos grupos. (FISCHER, B.T.D., 2009, pesquisa de campo)

Michel Foucault, Zygmund Bauman, Frederic Jameson e David Harvey, Nikolas Rose, Shirley Steinberg e Joe Kincheloe, entre tantos outros. São autores que me permitem olhar para as questões da educação que me interessam. Compõem uma matriz de inteligibilidade que me ajuda a pensar sobre a educação contemporânea. (COSTA, Vorraber M., 2009, pesquisa de campo)

Paulo Freire, Pedagogia do Oprimido; Maurice Merleau-Ponty, Fenomenologia da Percepção; Paul Feyerabend, Contra o Método, Pierre Bourdieu e Jean Claude Passeron, A reprodução; Mariano Fernández Enguita, A Face Oculta da Escola. Esses autores, lidos em etapas diferentes de minha formação intelectual, permitiram que eu desenvolvesse meu arsenal teórico-metodológico e orientaram-me em minha busca de objetos de investigação. (FERREIRA, M. O. V., 2009, pesquisa de campo)

Piaget/Freud/Vygotsky - pelo fato da obra deles ter me ajudado a compreender um pouco melhor os sentimentos, os pensamentos e as contradições da alma humana. (DUARTE, R. M., 2009, pesquisa de campo)

[...] minhas opções se justificam por trabalhar em uma área de fronteira, História, Educação e Ensino de História. (FONSECA, S.G., 2009, pesquisa de campo)

Micheal Parsons, Abigail Housen, Norman Freeman, Ana Mae Barbosa, Edmund Feldman. Esses autores fundamentaram minhas investigações na área do desenvolvimento estético-visual. (ROSSI, M.H.W., 2009, pesquisa de campo)

CATEGORIA II: Transformação de Saberes e Práticas com 133 respostas assim classificadas: 
Essa categoria é aqui definida "como o rompimento crítico com formulações teórico-conceituais acerca da sociedade e da educação que a um só tempo desmitifica, emancipa e desafia". Esse rompimento desemboca em análises críticas de referências paradigmáticas e de conceitos, o que permite ressignificar e reconstruir o conhecimento que prejulgava consolidado.

Nos últimos anos tenho trabalhado com as mesmas temáticas de minha vida profissional - a escola e seus professores -, porém com outras perspectivas teóricas para ampliar minha compreensão e a dos alunos e colegas com quem trabalho. Estou, no momento (há dois anos), retomando o meu foco de trabalho sobre a docência em sua perspectiva de múltipla relação, já com essa compreensão alargada. (MARIN, A. J. 2009, pesquisa de campo)

Pedagogia do Oprimido (Paulo Freire), A Geografia serve, antes de mais nada para fazer a guerra (Yves Lacoste), O discurso do avesso: uma crítica a geografia que se ensina (Ruy Moreira), As veias abertas da América Latina (Eduardo Galeano [que, considerando a época] valeu), A História da Riqueza do Homem (Léo Huberman). Todos eles foram importantes porque mostravam o ser humano como produtor e produto de uma história mais ampla, como ser político dominando mas podendo mudar a história (sua e do mundo), enfim, me ajudaram a me tornar um "materialista" (cada palavra que uso, exigiria explicar mais e mais). (KAERCHER, N.A., 2009, pesquisa de campo)

GARAUDY, Roger, O ocidente é um acidente; FREIRE, Paulo, Pedagogia do Oprimido; DURAND, Gilbert, As estruturas antropológicas do imaginário; JOSSO, M. C., Experiências de vida e formação; BACHELARD, G., A Filosofia do não. Esses autores e livros apontaram outras possibilidades para pensar as relações do homem com a natureza e, por conseguinte as implicações do nosso agir. (PERES, L. M. V., 2009, pesquisa de campo)

Paulo Freire, pela criação de um método de aprendizagem no contexto da cultura brasileira, no livro Conscientização. (WACHOWICZ, L., 2009, pesquisa de campo)

Karl Marx; Boaventura Santos; Wallerstain, [...] funcionam como lentes para interpretação dos problemas de modo crítico e propositivo. (AZEVEDO DE JESUS, S. M. S., 2009, pesquisa de campo)

Filosofia da Práxis, Adolfo Vasquez; Pela mão de Alice, Boaventura Santos; Escola e Democracia, Demerval Saviani; Intelectuais e a organização da cultura, de Gramsci; Sete Lições de Educação de Adultos, Alvaro Vieira; [pela] ênfase na visão crítica e emancipatória da sociedade e da educação. (VEIGA, I. P. A., 2009, pesquisa de campo) 
Mirzoeff, Una introducción a la Cultura Visual, pela conteporaneidade de um campo novo de estudos. (OLIVEIRA, M. O., 2009, pesquisa de campo)

Nossa formação era muito mais maturada, feita no tempo, com uma bibliografia extensa. Passei por fases de compreensão, mudanças, rupturas de paradigmas. (GERALDI, C. M. G., 2009, pesquisa de campo)

Na década de 70 um autor que me encantou foi Carl Rogers. Talvez porque vivêssemos em plena racionalidade técnica e Rogers era uma voz dissonante, que trazia o emocional como condição da aprendizagem e que tomava essa perspectiva numa condição humana. Como não lembrar-se do Tornar-se Pessoa? Outra lembrança importante foi 'Professores para quê?' 'de George Gusdorf. Trazia ele a compreensão do professor como ser humano, que tem dúvidas e receios, mas tem utopias $O$ início dos 80 desvelaram a nossa ingenuidade política. E já foram nacionais como Moacir Gadotti (texto na Educação e Sociedade número 1, que desvelava a relação da educação com a sociedade), Guiomar Namo de Melo com o 'Magistério de primeiro grau: da competência técnica ao compromisso político'e Demerval Saviani, na Filosofia da Educação, mostrando as tendências da educação. Creio que foram as minhas principais inspirações. Não há como negar a leitura de Freire como uma referência maior. Especialmente a Pedagogia do Oprimido que nos ajudou a compreender a educação como possibilidade de regulação, mas também como possibilidade de emancipação. Mais tarde o contato com os autores de sociologia da reprodução onde faço um destaque a Bourdieu e Basil Berstein. Com eles aprendi a fazer a relação entre a macro e a micro espaço educacional . Nos 90 me encontrei com Boaventura Santos e com ele fiz a teorização das mudanças paradigmáticas já por mim pressentidas e nominadas artesanalmente. Dialoguei com Tardif e Nóvoa na elucidação do conceito de saberes. (CUNHA, M. I., 2009, pesquisa de campo)

CATEGORIA III: Dimensão Teórico-Metodológica com 61 respostas assim classificadas:

Essa categoria é aqui definida como "construção de guias de referência para o desenvolvimento da pesquisa e da ação docente".

Miriam Limoeiro: pelas discussões sobre método, pela perspectiva materialista-histórico-crítica. (GATTI, B., 2009, pesquisa de campo)

Foucault, pela perspectiva teórico-metodológica que sustenta em investigações de dimensão histórica. (FISCHER, B. T. D., 2009, pesquisa de campo) 
Menga Lüdke parceira constante nas reflexões sobre formação docente e pesquisa, Maria Rita Oliveira nos escritos da Didática, Bernadete Gatti na pesquisa. (ANDRÉ, M., 2009, pesquisa de campo)

Carlo Guinzburg, pela formulação do paradigma indiciário. (PESSANHA, E., 2009, pesquisa de campo)

Durkheim, As regras do método sociológico, me introduziu as metodologias de investigação positivista, quando eu cursava sociologia; Max Weber, novas formas de pensar o método de investigação na fenomenologia e posturas teóricas de sociedade moderna em formação; Selltiz e outros, que me introduziu os ensinamentos técnicos de Métodos de Pesquisas nas relações sociais. [...] Boaventura dos Santos, novos enfoques teóricos e metodológicos tendo como eixo uma nova forma de sociedade alternativa; Peter Alheit, uma nova abordagem teórico-metodológica de trabalhar a qualificação e a formação de pessoas jovens e adultas (inclusive gênero), a partir de biografias de aprendizagens. (PRESTES, E. M. T., 2009, pesquisa de campo)

Norman Fairclough pelas questões metodológicas da análise do discurso. (CARDOSO, R. M., 2009, pesquisa de campo)

Bourdieu, Morin, Bachelard, Boaventura de Souza Santos e Moscovici-todos transitam várias áreas de conhecimento e contribuem para a minha compreensão de sujeito da história e de minhas opções como professora e pesquisadora, dando sustentação teórico-metodológica. (ABDALLA, M. F. B., 2009, pesquisa de campo)

Uso os estudos de Selma Pimenta e Lea Anastasiou nos saberes docentes e formação de professores da educação superior, as contribuições de Marli André, na perspectiva da etnografia; as reflexões sempre atuais de Freire, especialmente em Medo e Ousadia: o cotidiano do professor; Terezinha Rios e sua reflexão sobre ética e pedagogia das competências. Teria muitos outros, mas dispersos em textos e não em livros. (CUNHA, 2009, pesquisa de campo)

Marx, Contribuição à Crítica da Economia Política, pelo método de pesquisa utilizado [...], Miriam Limoeiro, idem. (WACHOWICZ, L., 2009, pesquisa de campo)

Bernardete Gatti, pouca gente sabe, como ela, unir pesquisa quantitativa e qualitativa.[...] Eni P. Orlandi, ampliou meus horizontes com suas publicações sobre Análise do Discurso. (BALZAN, N.C., 2009, pesquisa de campo)

Francisco Gutiérrez; Pierre Babin e Pierre Levy [... ] são autores que se debruçam sobre questões educativas com e através dos meios de comunicação. [...] Heloísa Penteado, Mirza Toschi e Vani Kenski, porque também estudam as mídias em diferentes contextos e porque 
somos companheiras no GT de Educação e Comunicação. (PORTO, T. M. E., 2009, pesquisa de campo)

CATEGORIA IV: Integração da Formação Pessoal e Profissional com Compromisso Ético com a Transformação Social com 60 respostas assim classificadas:

Essa categoria é aqui definida como "referente à inteireza do sujeito do afeto e da razão na constituição pessoal e profissional, nas relações e no genuíno compromisso com uma sociedade justa".

Maria Helena de Souza Patto: pelas análises sobre processos educativos e o fracasso escolar. (GATTI, B., 2009, pesquisa de campo)

Maria Helena de Souza Patto, obra que li sob a orientação da Professora Bernardete Gatti, em uma das disciplinas que cursei durante os estudos de mestrado (PUCSP). Um livro fortemente marcado, escrito com profundidade teórica e maestria de escrita [...] que me ajudou a pensar criticamente na minha responsabilidade social e política como pesquisadora e como formadora de professores. (DURAN, M. C. G., 2009, pesquisa de campo)

Freire/Brandão/Maria Isabel da Cunha, auxiliam-me na reflexão teórico-metodológica, tornam-me mais humana. (FORSTER, M. M. S., 2009, pesquisa de campo)

Paulo Freire, meu mestre, que me ajuda a entender a escola pública, a formação de minha consciência e dos professores e o respeito pelos alunos. (PONTUSCHKA, N. N., 2009, pesquisa de campo)

GIROUX, Henri. Também na ênfase à teoria crítica e defesa pela formação do profissional docente que se considere e saiba agir como intelectual, sem arrogância, mas com competência naquilo que ée faz. (GIESTA, N. C., 2009, pesquisa de campo)

Foucault, Homi Bhabha, Boaventura Souza Santos, autores que tratam das relações éticas - (portanto fundamentais ao campo educacional) e dão elementos para discussão sobre o pós-colonialismo (outra questão fundamental para discussão sobre a epistemologia colonial que permanece no campo educacional no Brasil). (CARVALHO, R. T., 2009, pesquisa de campo)

Saviani, Vera Candau, Robert Stake - pelos fundamentos na área de educação, pela relação humana na convivência de professores. (ANDRÉ, M., 2009, pesquisa de campo)

Além disso, as teorias pensadas por Nóvoa e Josso, esta numa perspectiva feminina, evidenciam uma epistemologia da formação que passa por uma 'construção de si'. Portanto, o exercício da docência $e$ as investigações sobre formação ocorrem num processo em que permanentemente a minha posição é revisitada, porque percebida 
como um projeto de vida que, embora individual, é construído no coletivo. Tenho insistido na validade do 'eu-e-nós' (roubado de Marcos Arruda) ou do 'eu-tu'(Buber), de buscar a alteridade e produzir sentidos para o que faço/penso/atribuo... Os autores citados, juntamente com outros tantos) ajudam a construir esses sentidos e a entender os processos formativos na profissão professor. (CHAIGAR, V. A. M., 2009, pesquisa de campo)

CATEGORIA V: Formação Docente, Cotidiano Escolar, Aprendizagem e Desenvolvimento com 50 respostas assim classificadas:

Essa categoria é aqui definida como "esclarecimento da trajetória teórica, tratamento da docência de forma contextualizada (macro e micro), questionamento do fazer pedagógico e da pesquisa, apresentação de elementos significativos para superar dilemas e organizar a formação de professores" da Educação Infantil à Pedagogia Universitária, permitirão ao ingresso nas preocupações nos/dos/com os cotidianos, análise da construção do conhecimento e trabalho com a dialética entre aprendizagem e desenvolvimento.

José Mário Pires Azanha: pelas análises refinadas sobre aspectos da política educacional e sobre estudos e pesquisas e educação. (GATTI, B., 2009, pesquisa de campo)

Admiro o Nóvoa, pelos escritos na história de educação e formação docente, Bob Satke pelos escritos sobre o estudo do caso etnográfico, Mrylin Cochran Smith pelos escritos na área de formação docente. Mas gosto do Apple, Giroux, Young, Carr e Kemmis, Zeichner, Charlot. [...] procuro estar atenta e atualizada em relação ao mercado editorial, não esquecendo de investir no campo da prática da pesquisa e da docência (em qualquer nível de ensino), uma vez que, felizmente, a produção de literatura é cada vez maior, diversificada e de qualidade, no entanto, as práticas nas escolas (inclusive na universidade), ou não estão apoiadas em teorias ou firmam-se em teorias que não dão conta de responder aos desafios contemporâneos, nas mais diferentes realidades. (ANDRÉ, 2009, pesquisa de campo)

A invenção do cotidiano: artes de fazer, de Michel de Certeau [partindo de reflexões na qualificação de Doutorado realizada por Wanderlei Geraldi, da UNICAMP, um dos examinadores e que] marcaram um ponto de inflexão na minha formação como pesquisadora, ou seja, houve um movimento de inversão de perspectiva, um deslocamento da atenção para um 'não lugar', aquele da criação anônima, nascida do desvio dos produtos recebidos, e que reconhece os discursos táticos dos consumidores. Tal movimento ofereceu as condições de possibilidade para que eu mergulhasse no cotidiano escolar, considerando a perspectiva de análise com interesse no exercício de um 'não po- 
der', ou seja, com as formas subterrâneas de conviver com políticas impostas, instituidas por um 'lugar de poder e de querer'. Refiro-me às relações instituintes, às burlas dos consumidores de tais políticas, de que nos fala De Certeau. Considerando as políticas educacionais, refiro-me às invenções dos professores e dos alunos, voltando-me para as maneiras de fazer - a pesquisa das práticas - para a lógica do cotidiano. (DURAN, M. C. G., 2009, pesquisa de campo)

Bernardete Gatti, por seu conhecimento e inserção na pesquisa e pós-graduação, focalizando de forma crítica e autêntica a formação docente e as práticas em contextos universitários. (GIESTA, N. C., 2009, pesquisa de campo)

Inclusão e Resistência: Educação Matemática e Legitimidade Cultural de Gelsa Knijinik, que me apresentou a abordagem etnomatemática - que utiliza com rigor e delicadeza - como uma possibilidade educativa e não apenas como um estudo antropológico. (FONSECA, M. C. F. R, 2009, pesquisa de campo)

Pimenta, Libâneo, e Mabel (Maria Isabel da Cunha) - a proximidade com a questão didática e da formação de professores. (ABDALLA, M. F. B., 2009, pesquisa de campo)

Paulo Freire, Marli André, Ilma Veiga, pelo que são no cenário educacional e na possibilidade da práxis cotidiana. (FERNANDES, C. B., 2009, pesquisa de campo)

Vigotski, pela dialética entre aprendizagem e desenvolvimento humano; Juan Ignácio Pozo, pela apresentação das teorias cognitivas de aprendizagem; Philipe Meirieu, pela coerência no estudo de Didática e da aprendizagem e pela definição do conhecimento como objeto específico do trabalho pedagógico. (WACHOWICZ, L., 2009, pesquisa de campo)

Atualmente uso Boaventura de Souza Santos, que me ajuda a fazer as pontes entre a macro e as micros estruturas sociais, com esperança; Carlos Marcelo Garcia que tem me ensinado a compreender as aprendizagens do adulto; Maurice Tardif e António Nóvoa, pela forma didática com que esmiúçam os saberes docentes [e.] que me ajudou a resistir às competências. Outros espanhóis foram importantes para mim, onde nomeio Gimeno Sacristan, Perez Gomes, Féliz Ângulo. Registro os escritos de minha amiga Elisa Lucarelli no campo da pedagogia universitária como importantes . Certamente a minha memória me trai e ela pode, muitas vezes, ser injusta!! Por isso peço desculpas àqueles que esqueci de nomear, e que foram muitos!!!. (CUNHA, M. I., 2009, pesquisa de campo)

Educação como prática da liberdade, Paulo Freire; O Conhecimento coapropriado e reapropriado pela classe operária, Thagtenberg; Educação: do senso comum à consciência filosófica, Saviani; são 
autores que esclarecem a trajetória teórica, questionam o fazer pedagógico e apresentam elementos significativos para superar dilemas e organizar a formação de professores. Desvelam a realidade social. (VEIGA, I. P. A., 2009, pesquisa de campo)

CATEGORIA VI: Bases do Marxismo, Método da Reflexão Dialética com 45 respostas assim classificadas:

Essa categoria é aqui definida como formulação das "bases para aprender as relações dialéticas entre educação e sociedade, para compreensão da escola capitalista, para o posicionamento político de esquerda, para a pedagogia de orientação marxista, para as teorias de aprendizagem de perspectiva histórico cultural, para a compreensão da educação como ato político pedagógico" com comprometimento sócio-político e fundamentação epistemológica coerente, para a indissociabilidade entre método de pesquisa e atuação política.

E. Mounier (Personalismo), Louis Lebret (Princípios para a ação), René Voillaume (Fermento na massa), livros de formação de meu posicionamento político de esquerda, na juventude, de orientação católica. Marx, Gramsci, Octávio Ianni - conhecimento das bases do marxismo e do método da reflexão dialética. Demerval Saviani, Georges Snyders, Bernard Charlot, Gramsci [sic] - primeiras influências em torno da formulação de pedagogia de orientação marxista. Mario Manacorda, Bogdan Suchodolskky - reforço dos princípios e elementos de pedagogia marxista. Lorenzo Luzuriaga, Jesus Palácios, P. Monroe, Frederichk Eby - História da Educação. Lev Vygotsky, Leontiev, Vasili Davidov-autores que nos 10 últimos anos são minhas fontes para as teorias de ensino e aprendizagem na perspectiva histórico-cultural (base sócio-cultural e psicológica). José Gimeno Sacristán, Perez Gómez - influência da cultura em suas ligações com a educação e o ensino, incluindo multiculturalismo e interculturalidade. (LIBÂNEO, J. C., 2009, pesquisa de campo)

[...] com eles (Saviani, Luiz Antonio Cunha, Gramsci, Makarenko e Marx) aprendi a relação dialética entre educação e sociedade. (ALVES, M. L., 2009, pesquisa de campo)

Hobsbawn e Perry Anderson porque são historiadores fantásticos e Trostky porque sem ele não dá para entender a transição e a revolução permanente. (TAFFAREL, C. Z., 2009, pesquisa de campo)

Antonio Gramsci, pela concepção dialética da História, [...], Alfredo Bosi, pela dialética da colonização. (WACHOWICZ, L., 2009, pesquisa de campo)

Karl Marx dispensa apresentação mas com suas leituras consolidei a percepção da indissociabilidade entre pesquisa e ação política. (PESSANHA, E., 2009, pesquisa de campo). 
Henry Lefèbvre - Lógica Formal/Lógica Dialética - fundamental para entender a questão do método numa visão do marxismo visto em um outro contexto da História da sociedade, sobretudo francesa. (PONTUSCHKA, N. N., 2009, pesquisa de campo)

CATEGORIA VII: $\underline{\text { Centralidade da Cultura na Compreensão da Escola e do }}$ Ensino com 22 respostas assim classificadas:

Essa categoria é aqui definida como influência na "compreensão da cultura em suas ligações com a educação e o ensino".

Paulo Freire, Tomas Tadeu da Silva, Marisa Vorraber, autores que têm a cultura como categoria fundamental para compreender os processos educacionais. (CARVALHO, R. T., 2009, pesquisa de campo)

Roger Chartier - para história cultural, livros, leitura, escritas de si, autor, etc. Ainda utilizo muito Guy Vincent, Dominique Julia, André Chervel, Antono Viñao Frago, todos fundamentais para a questão da cultura/forma escolar e compreensão das práticas educativas $e$ escolares, na perspectiva da histórica da educação. (BASTOS, M. H. C., 2009, pesquisa de campo)

CATEGORIA VIII: Fundamentos da Educação e Referências Clássicas alcançando 18 respostas:

Essa categoria é aqui definida como compreensão sobre "os fundamentos históricos, políticos, filosóficos da civilização ocidental acerca dos processos educativos" e pensadores fundamentais que deveriam ser lidos por todos.

Percebo que a partir da década de noventa houve um certo abandono de autores clássicos (que discutem fundamentos e teorias, e, aspectos chaves para as questões educacionais) em favor de textos que chamo de 'reprodutivos'. Autores-fonte de pensamento, tidos como 'difíceis', não são estudados. (GATTI, B., 2009, pesquisa de campo)

[...] porque compõem referências clássicas das abordagens contemporâneas que trabalho [...]. (GERALDI, C., 2009, pesquisa de campo)

[...] a volta aos clássicos penso ser fundamental, pois essa revisitação nos faz reentendê-los e contextualizá-los; ajuda-nos, junto com os alunos/grupo de pesquisa, a entender a origem do que se fala. Lógico que sem nostalgia, podemos avançar na direção de novos desafios [...] (FORSTER, M. M. S., 2009, pesquisa de campo)

Os clássicos da historiografia - antigos e contemporâneos (principalmente, Bloch, Le Goff e Ginzburg). (GARNICA, V., 2009, pesquisa de campo) 
CATEGORIA IX: Estilo, Estética e Consistência Teórica dos Autores com 12 respostas assim classificadas:

Essa categoria é aqui definida como "originalidade, organização e clareza na escrita, rigor, poder de síntese, amplitude de idéias e temas", lucidez e consistência teórica.

Marcos Villela Pereira, pela sua estética de professoralidade, abrindo caminhos para a discussão sobre a possibilidade de cada professor produzir-se professor de acordo com o que lhe faz sentido. (JUNQUEIRA FILHO, G. A., 2009, pesquisa de campo)

Os contos de Machado de Assis fundamentais para aprender mecanismos de elaboração textual que, embora não sejam propriamente acadêmicos, contribuem sobremaneira para a clareza da exposição do pensamento. (GARNICA, V., 2009, pesquisa de campo)

Maria Manuela Garcia, aprecio demais a originalidade e a profundidade com que olha a docência, com um olhar foucaultiano, e a organização e a clareza com que escreve; Alfredo Veiga-Neto, também saliento o rigor, a profundidade e a coerência de sua escrita, assim como a amplitude de temas que, inteligentemente, aborda; Marisa Vorraber Costa, aprecio seu poder de síntese, de aplicação e de releitura de autores que às vezes nos chegam menos claros. (2009, pesquisa de campo $)^{23}$

Provocar nossos interlocutores sobre os livros de literatura que foram recorrentes em sua formação, pareceu importante, numa visão alargada desse processo, procurando ampliar a possibilidade de compreensão de suas trajetórias.

Dentre os autores de literatura considerados por eles como marcantes, encontram-se: Érico Veríssimo (18 indicações); Machado de Assis (15 indicações); Clarice Lispector (13 indicações); Guimarães Rosa (12 indicações); Gabriel Garcia Márquez (9 indicações); Fernando Pessoa; Graciliano Ramos; Jorge Amado (6 indicações); José Saramago; Saint Exupéry; Monteiro Lobato; Isabel Allende (5 indicações); Mario Vargas Llosa; Thomas Mann; Ítalo Calvino (4 Indicações)

As escolhas, todas de clássicos, corroboram a análise de Frye (1973), quando afirma que a ficção narrativa em prosa é o gênero literário da modernidade, bem como as de Calvino (2007, p. 10-11) ao referir-se à leitura dos clássicos. Afirma o autor que:

são livros que exercem uma influência particular quando se impõem como inesquecíveis e também quando se ocultam nas dobras da me-

23 Eventualmente, quando um dos sujeitos da pesquisa não tenha encaminhado autorização escrita para publicação de seu nome, a citação foi usada desta forma. 
mória, mimetizando-se como inconsciente coletivo ou individual [...]. São aqueles livros que chegam até nós trazendo consigo as marcas das leituras que precederam a nossa e atrás de si os traços que deixaram na cultura ou nas culturas que atravessaram (ou mais simplesmente na linguagem ou nos costumes). ${ }^{24}$

O peso das escolhas de clássicos reforça o entendimento dos efeitos que esta qualidade de literatura produz no "afinamento de alma" dos leitores e, quiçá, seja mais um indicativo de que nossos estudantes também devessem lê-los. O significativo número de autores brasileiros, latino-americanos ou de língua portuguesa e hispânica, que era o que estava mais a nosso alcance, pelo menos nos últimos 40 anos, poderia ser entendido também pelo fato de que literatura pressupõe certo grau de intimidade com a língua em que é lida, diferentemente daquilo que trata do científico. ${ }^{25}$

\section{Da comunidade epistêmica e seus referenciais: algumas considerações finais}

Ainda que relativizando as respostas dos sujeitos da pesquisa, a partir do lugar político e epistemológico que ocupam, é possível, através da "história das leituras" (CUNHA, 2009, pesquisa de campo) traçar as trajetórias individuais e, ao mesmo tempo, desenhar indicadores da história de uma comunidade epistêmica.

Assim, mesmo tendo como pressuposto que "nenhum autor escape dos contextos socioculturais e institucionais em que viveu e atuou" (LIBÂNEO, 2009, pesquisa de campo) e que "a importância [conferida a uma obra ou autor dependa] da época e das necessidades que [cada intelectual] sentia no momento em que [encontrou-se] com o autor [o que caracteriza] uma localização da significação" (CUNHA, 2009, pesquisa de campo), consideramos que "um pesquisador qualificado trabalha [em um] campo semântico e [em] uma matriz de inteligibilidade que balizam e subsidiam seu pensamento e ajudam a compor seu arsenal analítico [...] constituído, sem sombra de dúvida] de não apenas três ou quatro autores, mas [de] um conjunto (sempre crescente) de pesquisadores e ensaístas que realizam análises afinadas com esta matriz [e que] constitui o

24 Sem diminuir a importância de Érico Veríssimo, clássico inconteste da literatura brasileira, talvez o fato de ter aparecido com mais citações do que Machado de Assis seja decorrente de que os gaúchos são sabidamente valorizadores do que lhes é "da terra" e, neste ENDIPE, eram a maioria dos simposistas, conforme indicação anteriormente feita.

25 Agradeço ao Professor Doutor Benito Martinez Rodriguez (UFPR) pela gentileza fraterna das indicações bibliográficas relativas à análise literária e me responsabilizo pelo uso que fiz delas. 
referencial para o trabalho investigativo, para as análises e para as propostas de ensino." (COSTA, Vorraber M., 2009, pesquisa de campo).

A população escolhida para essa pesquisa, como afirmado anteriormente, nos parece representativa de uma comunidade epistêmica (ANTONIADES, 2003). Entendemos, como Lopes (2006, p. 33-52), que "os discursos produzidos pelas comunidades epistêmicas têm, potencialmente, a capacidade de influenciar textos políticos e a formação de professores nos contextos de produção de políticas".

A idéia inicial, como já referido anteriormente, era a de identificar as representações e referências que estão presentes nos autores que qualificam as práticas de formação, em especial da educação superior, buscando identificar as bases teóricas que sustentam os indicadores de qualidade do ensino e da pesquisa e as ações de desenvolvimento dos mesmos.

Foi possível observar que, guardadas as distintas especificidades, a preocupação com as relações entre saber e poder bem como com a historicidade da formação do professor dá-se de maneira contundente. Há, de parte dos sujeitos dessa pesquisa, o que se pode denominar de "sujeitos endereço" na área da Didática e das Práticas de Ensino no país, que defendem uma explícita opção epistemológica voltada para as teorias críticas e/ou pós-críticas e pós-colonialistas que nos permitem ver a educação de uma nova perspectiva ao retirarem o foco de conceitos simplesmente pedagógicos de ensino e aprendizagem e colocaremno na análise dos conceitos de ideologia e poder, ou mesmo ao enfatizarem o conceito de discurso, como no dizer de Tadeu da Silva. (2009, p. 17)

A pesquisa evidenciou, da parte dos sujeitos com mais tempo de formação, a existência de um trajeto em busca do rompimento com dimensões epistemológicas e com a própria compreensão política do papel da escola, sempre em direção a uma pedagogia mais crítica, humana, social, histórica e dialética. Esta atitude também é facilmente comprovada nas gerações posteriores de sujeitos com menos tempo de Doutorado, o que sugere uma possível tatuagem do ensinar, o insignare.

É possível constatar, também, que os autores nacionais que vêm influenciando a produção contemporânea reconhecem como marcas importantes de sua formação $0^{26}$ os seguintes pensadores e conceitos:

a) Paulo Freire (21 indicações): constitui uma unanimidade tanto na formação como na pesquisa e na docência. O livro Pedagogia do

26 Tomo aqui como suporte para análise aqueles autores que receberam, pelo menos, três citações como sendo os mais importantes na formação dos sujeitos entrevistados. 
Oprimido, que segundo Tadeu da Silva (2009, p. 57) é o que "melhor representa o pensamento pelo qual ele iria se tornar internacionalmente conhecido e reconhecido", é, para os sujeitos da pesquisa, emblemático no sentido da compreensão da educação como prática da liberdade, como emancipação. ${ }^{27}$ Assim, Freire parece constituir, parodiando Göethe, citado por Freud (1974, p. 188), a herança que todos desejariam conquistar para que um dia pudesse ser sua; seja por sua "coerência entre comprometimento sócio-político e fundamentação epistemológica, seja pela criação de um método de aprendizagem no contexto da cultura brasileira, seja pela ética, seja pela estética, seja pelo que de humano imprime ao ato de educar".

b) Marx (13 indicações $)^{28}$, Gramsci ( 8 indicações) e Kosik (5 indicações) são autores cuja compreensão da educação e do conhecimento se dá pelo entendimento de que são as relações sociais de produção que as condicionam e determinam (MARX, 1946); de que existe um sujeito que não sendo parte da classe trabalhadora é sujeito de classe, que tem papel fundamental na formação, na consciência, na emancipação, que é o intelectual orgânico ${ }^{29}$; que trabalha o conceito de hegemonia ${ }^{30}$, e traçou uma equação político-pedagógica (GRAMSCI, 1985; GROUPPI, 1978) que para conhecer o objeto é preciso conhecer não o fenômeno mas sua estrutura (KOSIK, 2002);

c) Demerval Saviani (9 indicações): autor que nos anos 80 desenvolve uma pedagogia intitulada "pedagogia histórico-crítica" ou "pedagogia sócio-cultural dos conteúdos" e cuja sistematização e análise sobre as tendências da Educação também serviram de matriz de compreensão fundamental para os professores/pesquisadores. Discute, até hoje, crítica, e politicamente contextualizada a democracia e a sociedade na instituição escolar.

d) Althusser (3 indicações) e Lefèbvre (4 indicações), ambos marxistas, sendo o primeiro influenciado pelo estruturalismo e o segundo um dos primeiros a criticar a concepção estruturalista. Althusser é amplamente

27 Vale apontar que quando questionados sobre que livro gostariam de ter escrito, os respondentes da pesquisa, indicaram autores e livros totalmente distintos uns dos outros à exceção do Pedagogia do Oprimido que se repetiu por quatro vezes. Sem contar que livros outros do próprio Freire também foram citados.

28 Número de citações.

29 "Conceito posteriormente usado como base para Giroux (1997), que vê as professoras e os professores como 'intelectuais transformadores'."

30 "Posteriormente desenvolvido por Raymond Williams e utilizado por Apple [citado duas vezes na formação e três vezes no uso na docência e na pesquisa].” (SILVA, 2009, p. 46) 
conhecido como um teórico das ideologias. Althusser foi o primeiro crítico-reprodutivista, denunciando "caráter perverso da escola capitalista" e enfatizando o aspecto reprodutor da escola. A escola é vista como reprodutora porque fornece às diferentes classes e grupos sociais, formas de conhecimento, habilidades e cultura que não somente legitima a cultura dominante, mas também direcionam os alunos para postos diferenciados na força do trabalho, sendo que nenhum outro Aparelho Ideológico de Estado dispõe de uma audiência obrigatória por tanto tempo e durante tantos anos, precisamente no período em que o indivíduo é mais vulnerável. Althusser, quando analisa o papel do currículo no processo de reprodução, "enfatiza o papel do currículo explícito, do oficial, do conteúdo do currículo" (SILVA, 2009, p. 47). Lefèbvre foi um filósofo marxista que criticou o economicismo estruturalista que dominava o discurso acadêmico de sua época, argumentando que a produção social do espaço urbano era fundamental para a reprodução da sociedade e, por conseguinte, do capitalismo. Lefèbvre usa o conceito de hegemonia, proposto por Gramsci, como uma referência para mostrar como a produção social do espaço é comandada por uma classe hegemônica como uma ferramenta para reproduzir a sua posição dominante. Lefèbvre posiciona-se contra o dogmatismo que, para ele, transforma o marxismo em ideologia, pondo-se a favor da dialética, entendendo que a luta se dá mediante a elevação da práxis ao nível do conceito e pela vivificação do conceito na prática;

e) Snyders (4 indicações), apresenta-se como marxista leal mas não dogmático cujo pensamento pedagógico se mostra totalmente vinculado à sua militância política;

f) Bachelard (4 indicações) reflete sobre os métodos, o contexto cultural, a gênese, estrutura, funcionamento, alcance e limites do conhecimento científico;

g) Weber (3 indicações) estuda a burocracia e a caracteriza como poder e dominação;

h) Bourdieu (12 indicações) ${ }^{31}$ que sempre admitiu o papel importante da Educação no trabalho por ele desenvolvido. A partir de uma forma de conhecimento praxiológico, mediando objetivismo e subjetivismo e compondo um estruturalismo genético, o sociólogo francês considerava que o sistema de escolar e o desvelamento de suas lógicas internas,

31 Passeron, co-autor da obra A Reprodução é citado apenas três vezes. 
poderia ser uma ocasião privilegiada para estudar os fenômenos de transmissão cultural, bem como a transmissão de estruturas mentais e de sistemas de classificação. A partir de conceitos como o de habitus, campo, capital cultural, violência e poder simbólicos, Bourdieu propôs uma Sociologia científica original centrada na cultura escolar, "uma pedagogia e um currículo que reproduzam, "na escola", para as crianças das classes dominadas, aquelas condições que apenas as crianças das classes dominantes têm na família." (SILVA, 2009, p. 36);

i) Foucault (7 indicações) cujo entendimento do poder, concebido como relação, contrapõe-se ao entendimento dado pelo marxismo. Por ser relação, em sua compreensão, está em todas as partes o que faz com que toda e qualquer pessoa seja atravessada por relações de poder, não podendo ser considerada independente delas. Para Foucault, o poder não somente reprime, mas também produz efeitos de verdade e saber, constituindo verdades, práticas e subjetividades. O autor, também em contraposição ao marxismo, entende poder e saber como mutuamente dependentes.

j) O estatuto dos saberes pedagógicos, a disciplinarização dos saberes, via currículo, o controle dos sujeitos são apenas alguns dos temas estudados mediante a forma de entendimento foucautiana. Michael Apple (2 indicações) ${ }^{32}$ parte dos elementos centrais da teoria marxista, mas se diferencia ao analisar o vínculo entre a relação da economia com a educação postulando uma mediação ativa da ação humana, questionando a cultura como reflexo da economia e atribuindo-lhe uma dinâmica própria;

k) Boaventura Santos (6 indicações) adota uma visão pós-colonialista, uma perspectiva ética com a transformação social e uma concepção baseada na esperança da superação dos dilemas da sociedade contemporânea;

l) Antonio Nóvoa (4 indicações) conhecido pela questão da dimensão histórica da formação de professores e também pelo compromisso ético com a transformação social;

m) Rogers (3 indicações) trouxe para a compreensão da aprendizagem a dimensão afetiva como fundamental quando o que vigorava era a racionalidade técnica;

Citado apenas duas vezes na formação mas três no uso na docência e na pesquisa. 
n) Piaget e Vygotsky (3 indicações cada um) explicaram o funcionamento da inteligência e de sua construção pela criança em interação com o real e o social;

o) Tadeu da Silva (3 indicações) conhecido pela compreensão crítica que elabora e propõe sobre as teorias de currículo;

p) Carlos Marcelo Garcia (1 indicação) ${ }^{33}$ nas pesquisas sobre formação de professores tem centrado sua atuação em como os professores e estudantes adultos aprendem. Desde 2008 coordena uma plataforma virtual de ensino na Universidade de Sevilha para formar professores em recursos pedagógicos baseados no E-learning;

q) Kenneth Zeichner (1 indicação) ${ }^{34}$ também trabalha com o tema da formação de professores e sua preocupação maior é a de formar profissionais com condições de dar uma educação de qualidade para os filhos das classes populares e vítimas do preconceito e da discriminação.

Importante ressaltar que não se observa, na comunidade epistêmica aqui representada, nem endogenia nem colonização. Observa-se que existem autores brasileiros reconhecidos como referência para todas as áreas do ENDIPE (sendo que sete dos que possuem maior número de citações são sujeitos dessa pesquisa $)^{35}$. Entretanto, não se observam menções de uma mesma instituição ou grupo e nem se constata uma vinculação dogmática com uma matriz produtora de concepções locais ou internacionais. As indicações não se fazem sem avaliações críticas.

É na fala da professora Alice Lopes, atual coordenadora do Fórum de Coordenadores de Programas de Pós-graduação em Educação, como sujeito da pesquisa, que se faz possível referendar o fato de que existe no país uma geração de formadores brasileiros, cuja influência tem marcado as gerações de novos formadores. Uma comunidade epistêmica, reconhecida como tal pelos pares, que precisou se auto-instituir no Brasil, dado que a realidade assim demandou, que precisou "metamorfosear-se" e que o fez mediante o esforço do estudo, da produção intelectual, da orientação e docência e da gestão universitária, que continua ainda a exercer forte influência sobre os formadores.

33 Citado apenas uma vez na formação mas quatro na docência e na pesquisa.

34 Não citado na formação mas citado quatro vezes na docência e na pesquisa

35 Por ordem alfabética: Bernadete Gatti; Ilma Veiga; José Carlos Libâneo; Maria Isabel da Cunha; Marli André; Marisa Vorraber da Costa; Newton Balzan. 
Em minha graduação, lembro como foram marcantes os livros Pedagogia do Oprimido de Paulo Freire e Escola e Democracia de Demerval Saviani. Foi a partir desses textos que optei por continuar, em nível de Mestrado, com estudos em Educação. No Mestrado, foram extremamente marcantes as leituras, dos diálogos de Platão, de Perelman e dos textos de Bachelard, orientadas por José Américo Motta Pessanha. Nesse caso, para citar apenas um livro, o que é extremamente difícil, opto pela Filosofia do Não de Bachelard. Também foram importantes a leitura de Marxismo e Filosofia da Linguagem, orientada por Circe Navarro Vital Brazil e a leitura de Concepção Dialética da História, de Gramsci, orientada por Gaudêncio Frigotto. No Doutorado, os autores da perspectiva crítica, dentre eles Giroux e McLaren, orientados por Antonio Flávio Moreira. Saliento os professores que me orientaram nessas leituras, pois considero que não é o livro em si que nos marca, mas como foi lido e como foi orientada sua leitura em dado contexto. Saliento, ainda, que uma leitura marcante não é necessariamente uma leitura com a qual concordamos plenamente, mas aquela que se mostra importante para a construção de argumentos e de discussões teóricas, mesmo que estes sejam contrários à leitura que os gerou. (LOPES, A. C., 2009, pesquisa de campo)

Inicialmente, como mencionado, havia uma curiosidade sobre os referentes teóricos que os autores nacionais, que vêm influenciando a produção contemporânea na Didática e nas Práticas de Ensino, reconhecem em seu pensamento e produção. Os sujeitos da pesquisa, intelectuais que são, conforme a concepção de Zolá (1898, p. 1), parecem "ter escrito um poema" (ANDRADE, 1999, p. 60), digo, uma aula.

\section{Referências}

ANDRADE, C. D. de. Sentimento do mundo. Rio de Janeiro: Record, 1999.

ANDRÉ, M. Tendências da pesquisa e do conhecimento didático no início dos anos 2000. In.: EGGERT, Edla (Org.). et al. Trajetórias e processos de ensinar e aprender: didática e formação de professores: livro 1. Porto Alegre: EDIPUCRS, 2008. p. 487-499.

ANTONIADES, A. Epistemic comunities, epistemes and the constructions of (world) politics. Global Society, Kent, Inglaterra, v. 17, n. 1, 2003. 
CALVINO, I. Por que ler os clássicos. São Paulo: Companhia das Letras, 2007.

DIAS, R. E. Redes políticas de formação de professores. In.: ENCONTRO NACIONAL DE DIDÁTICA E PRÁTICA DE ENSINO, 14., 2008, Porto Alegre. Anais... Porto Alegre: Puc-RS, 2008.

FARIA, J. H. DE. Introdução à epistemologia crítica em estudos organizacionais. Curitiba: EPPEO, 2009. Working Paper.

FREUD, S. Escritores criativos e devaneios. Rio de Janeiro: Imago, 1976. FREUD, S. Totem e tabu. Rio de Janeiro: Imago, 1974.

FRYE, H. N. Anatomia da crítica. São Paulo: Cultrix, 1973.

GIROUX, H. A. Os professores como intelectuais. Porto Alegre: ARTMED, 1997.

GRAMSCI, A. Os intelectuais e a organização da cultura. 5. ed. Rio de Janeiro: Civilização Brasileira, 1985.

GROUPPI, L. O conceito da hegemonia em Gramsci. Rio de Janeiro: Graal, 1978.

KOSIK, K. A dialética do concreto. 7. ed. Rio de Janeiro: Paz e Terra, 2002.

LOPES, A. C. Discussões das políticas de currículo. Currículo sem fronteiras, v. 6, n. 2, p. 33-52, jul./dez.2006. Disponível em: $<$ http://www. curriculosemfronteiras.org/vol6iss2articles/lopes.pdf>

MARX, K. El capital: crítica de la economía política. Buenos Aires: Biblioteca Nueva, 1946.

SILVA, T. T. DA. Documentos de identidade: uma introdução às teorias de currículo. 3. ed. Belo Horizonte: Autentica, 2009.

ZOLA, E. J'accuse. L’Aurore. Paris, 13 jan. 1898. 